\title{
Prevention Strategies for HIV in Youth: A Concept Analysis
}

\author{
Sondang Ratnauli Sianturi ${ }^{1}$
}

\begin{abstract}
Purpose: To provide nurse educators how to address the problem of HIV/AIDS in the youth through the concept of prevention strategies

Methods: Review articles published during 2005 until 2014 that focused on HIV/AIDS prevention strategies. The databases used in this study were EBSCO, Medline, CINAHL, PubMed.

Result: HIV knowledge is an important factor influencing HIV risk perceptions and risk behaviors especially among youth. The concept of prevention strategies designed and tested to address risk behavior on young people at every step along their developmental path. Strategies are very important ways for preventing HIV/AIDS, especially in youth. Conclusion: The attributes that characterize the concept of strategies are: plan, process, studying different ways, focusing on the greatest need, and analyzing and learning. Although strategies are used in prevention, they are not maximized in Indonesia. The best strategies for the different age groups have not yet been determined. With use of the best strategies, nurse educator can teach nursing students how best to reach youth and other people in the community to prevent HIV.
\end{abstract}

Keywords: HIV/AIDS, Prevention, Youth, Strategies

1 Lecture at Sint Carolus School of Health Sciences, JL.Salemba Raya No.41, Jakarta Pusat 10440.

Email: sondangrsianturi@gmail.com 


\section{BACKGROUND}

HIV/AIDS is a disease that causes negative impact on all aspects of life, especially in young people. Young people are important to society as they are the future and are needed to assist in the development of Indonesia. Today, many young people in Indonesia have been diagnosed with HIV/AIDS. This rising number of young people contracting HIV/AIDS is due to many factors, such as the lack of knowledge and stigma about the disease itself, the discrimination of people suffering from this disease, free association with sexual practices, and the lack of attention from their family.

Indonesia has many people who are living with HIV/AIDS, especially in Jakarta. Statistics from the Ministry of Health Republic of Indonesia (2014) notes that Jakarta is the city with the most people living with HIV/AIDS with $69,1 \%$ of the people identified as living with the disease.. In addition, 577 have died from HIV/AIDS in 2011. Cumulative AIDS cases are 13,109 cases in young people between ages 15 - 29 years old. Children \& Youth Unit, the World Bank (2006) stated that the numbers speak for themselves. Everyday 5000 to 6000 young people's age 15-24 contracts HIV. With youth at the heart of the pandemic, HIV prevention must focus on young people. The Millennium Development Goal stated that increasing the knowledge of 15-24 year olds with HIV/AIDS is the primary goal and indicator of health.

Although today's youth are much more informed about HIV/AIDS than previous generations, even in countries with a general pandemic, more than $80 \%$ of young women still do not have "sufficient understanding" about how to avoid HIV ( World Bank, 2006). In addition, there are problems with the prevention of HIV among young people because there is still a high stigma and discrimination related to HIV/AIDS. Sometimes, information about HIV is not appropriately delivered to the youth. The current method of education is giving some information about health education, sex education and gender issues. The young people in Indonesia have little information from doctors or nurses who visit schools. There is also limited teaching about sex education, STDs, and HIV/AIDS. In addition, there is a lack of curriculum that includes sex education and reproductive health in young children. Today, the youth of Indonesia are increasingly being influenced to try something new due to exposure to technology such as the internet, Facebook, Twitter, and other social networking. Youth are much more sexually active at a younger age. There is also a rising use in tobacco, alcohol, and other drugs.

Therefore, there is a need for appropriate prevention strategies for young children in the education and knowledge of HIV/AIDS. This can lead to a positive impact for young people, so that the incidence and prevalence of HIV /AIDS on young children can be reduced. There is a need for strategies that can approach the various parties in contact with young people and HIV/AIDS. This means approaches to HIV/AIDS prevention must come from individual, peer, family, school, and community programs. Schools and families can be important partners for reaching youth before high risk behaviors are established, because school is a primary level for youth social development and family is a place that provides structure and guidance to youths about sexuality, because family has the social power to teach youth socially acceptable behavior. 
The analysis of concepts is a longstanding issue, both in philosophy and nursing. Concepts are called "the building blocks of theory" (Walker \& Avant, 2005). The Walker and Avant Method of concept analysis will be used to perform this concept analysis paper. Concept analysis is a process that identifies unique attributes of a concept, provide precise operational definitions of the concept, and improve communication regarding the concept (Walker \& Avant, 2005).

As nurse educators, it is important to teach health in different places, one of which is in the school. Programs run by a nurse educator at a school, teach children prevention and promotion of health. Prevention and promotion strategies are used to improve community health status. By providing education to children in school, the younger generation of Indonesia can be healthier and contribute to the future development of the country.

The concept of "Prevention Strategies for HIV in Youth" was chosen for this concept analysis because there is a need to explore and define what this concept is, so it can be applied to the rising rates of HIV/AIDS in the young people in Indonesia. For this concept analysis the focus of the literature review is the word "strategy". The long range goal of this work is to provide information, raise awareness, and encourage the development of safe behavior to minimize the risk of infection, change in perception among youth about HIV/AIDS, and develop better prevention strategies for youth. Finally, if these goals can be reached, there will be better solutions to the current problems associated with HIV/AIDS in Indonesia.

\section{METHODS}

The researcher search materials and data by doing the literature review based on journals from EBSCO, Medline, CINAHL and Pubmed with 19 articles. These articles were published during 2005 until 2014 about HIV/AIDS prevention and HIV/AIDS strategies in youth.

\section{RESULT}

\section{Strategy in Mathematics}

The theory called "Games of Strategy" may be described as a mathematical theory of decision-making by participants, in a competitive environment. A game of strategy is described by its set of rules. These rules specify clearly what each person called a "player" is allowed or required to do under all possible circumstances. Dresher (1961) defines strategy as a concept where a person makes a decision at every move. Each player formulates in advance of the play, a plan for executing the game from beginning to end. A player using a strategy loses no freedom of action since the strategy specifies the player's actions in terms of the information that might become available. Every pair of strategies, consisting of one strategy for each player, determines a play of the game to consist of each player's making one decision, namely the selection of a strategy (Dresher, 1961). 


\section{Strategy in Education}

A strategic imperative in low-income countries is a more explicit focus on the issue of dropouts, repetition, and completion rates. This relates directly to upgrading the quality and the relevance of the basic education delivery system, which in turn depends on the quality of teaching staff, the pedagogies used, and the participation and involvement of local communities.

The most obvious strategic area of focus is expanding the capacity of education systems to widen access toward universal primary education. Included would be identification of optimum areas for additional classrooms and physical facilities, expansion of budgets for additional teachers, and provision of textbooks and other learning materials. (Asian Development Bank, 2008).

Prakash Nair (2008) defines the strategy in education that Civitas Academica in school has their own strategy in teaching students. The teacher must find different ways to teach the student. Additionally, some strategies are more relevant to younger students, while others apply only to older students. Few innovation strategies can succeed without real leadership. However, in the world of education, good leadership at the top alone is not enough to improve student achievement.

\section{Strategy in Management}

USAID (2005) defines the heart of the strategy as basic education: facilitating the acquisition of basic skills, such as literacy, numeracy, and critical thinking that enable people and nations to thrive in a changing economic environment. USAID's strategies emphasize the following strategic management principles are focused on countries with the greatest need and commitment, enhance host-country efficiency; emphasize project sustainability.

Mc. Donald reports that strategic management is a process through which organizations analyze and learn from their internal and external environments, establish strategic direction, create strategies that are intended to move the organization in that direction, and implement those strategies, all in an effort to satisfy key stakeholders. Larger companies tend to use the strategic management process, this process is also a vital part of decision making in smaller companies. The strategic planning process tends to be a rather rigid and unimaginative process in many organizations. In other words, strategy should be both deliberate and emergent, and firms should both adapt to and enact with their environments. The situation determines which option to choose. In recent years, another perspective on strategy development has gained wide acceptance.

A strategy can be thought of in either of two ways, as a pattern that emerges in a sequence of decisions over time or as an organizational plan of action that is intended to move a company toward the achievement of its shorter-term goals and, ultimately, its fundamental purposes. In some organizations, particularly those in rapidly changing environments and in small businesses, strategies are not planned in the formal sense of the word. In those cases, the strategy reflects the insight and intuition of the strategies or business owner, and it becomes clear over time as a pattern in a stream of decisions. 


\section{Strategy in Nursing}

There are many variations to Wilson's method (Avant, 2000) in nursing. An example is analysis of pain management. Pain management is accepted in nursing as an integral component of the nurses' mission in providing nursing care to clients. Davis (1992) used a concept analysis strategy to identify the role of patient involvement in managing their own pain. As a process that nurses experience frequently, understanding the properties and outcomes of interruption could lead to an effective program of research related to its outcomes on nurses and patients (Brixey, Robinson, Johnson, et al., 2007). This strategy is based on collaboration, critical thinking, and expertise of participants, complementarity, mutual trust building, and mutual consensus building (Meleis, 2007). O'Neill (2000) said that strategy is the importance of bringing together the 'hard' elements (structure, rewards) of strategic management and the 'soft' elements of organizational development (processes, culture, interpersonal relationship) is relevant to nurses today as they attempt to grapple with the need for commitment to professional 'hands on' caring expected by the public and the pressure to be more politically aware and involved in management.

\section{DISCUSSION}

Researchers found that the characteristics relevant to strategy are integrated in many disciplines, including nursing, games, and management. The attributes identified from the literature review are: plan, process, studying different ways, focus on greatest need, along with analyzing and learning. Therefore, primary prevention strategies require a plan with an identified process based on the study of different ways to focus on the greatest needs with a continuous analyzing and learning of how to best address HIV/AIDS.

The first attribute on this concept is "plan". A plan is an important ingredient in any strategy. Without a plan efforts can be scattered and there is not a clear direction on what comes first, second and third. A plan is a scheme or method of acting, doing, proceeding, making, or advancing (dictionary, 2011). The plan must be effective, written, and clear, based on the real current situation. There also must be sufficient time for implementation and evaluation of a plan before moving onto another strategy. It should not be rushed. Rushing the plan will cause problems. The plan is used to guide policy, planning, and design decisions during implementation (Litman, 2011).

The second attribute on this concept is "studying different ways". In developing a strategy it is important to identify all the different ways in which the goal can be achieved. At the same time it is important to understand what is successful in different settings for different age groups and people. Young people think in accordance with the needs, interest, expectations, motives, and psychology of youth. Young people can learn in different ways. It is important to stimulate the various parties to provide information in different ways. Studying different ways refers to the concept that individuals differ in regard to what mode of instruction or study is most effective for them, so it means that different people learn information in different ways (Pashler, McDaniel, Rohrer, and Bjork, 2011). 
The third attribute is "focusing on the greatest need". In developing a strategy there is a significant focus on where the greatest need is or where resources can be used to have the best outcome. Every event or activity has a goal, and the goal is to focus on where there is the greatest need.

The fourth attribute is "analyzing and learning". When working in a strategic manner it is important to always be analyzing and learning from what is being studied and implemented. This is one of the only ways in which strategies can be improved. This attribute can be actualized when the program is being formed, when it is implemented and when it has been evaluated. Analyzing and learning is important in evaluation in order to effectively assess the impact of youth programs on the change in HIVprevention behaviors.

The last attribute is a "process". Strategy development is an ongoing process. King (2007) said analysis of collaborative learning interactions have demonstrated that what happens on the process level is important for predicting what cognitive benefits participants in a conversation take away from it.

Those attributes can help understand better what is meant by the concept "strategies". By employing better strategies in the prevention of HIV/AIDS young people will hopefully make more responsible choices about sexual behavior and practices. Working with communities, teachers, school councils, parent-teacher associations and learners themselves to assess, plan, implement, monitor, and evaluate education interventions will help improve program quality and ensure cultural sensitivity.

This is an example of the concept. A nursing student is in her "community health clinical studies" assignment. The first step is "community assessment". In this step the student must try to approach the people in that community. The assessment result is "The people's need more information on HIV, particularly on young people". They need more information about HIV because the behavior of young people in that community is at high risk for developing HIV. This request was forwarded by the student to the faculty. After receiving the faculty's approval, the students create a plan about educational activities for the young people in the targeted community. At the first stage, the student hold a meeting with the local government to receive some information about HIV cases and condition related to it, and also discuss about the convenience date of the proposed activity to be held. After that, the student will study further about the selected topic and discuss different and creative ways that the education can be provided. Finally, the students provide education and information about HIV to the young people in the community by using different media to explain the reproductive organs and using video animation to explain the causes of HIV. This was determined as the subjects where the students had the greatest need for education. The nursing students develop a test for the young people to be given before and after the educational program in order to estimate the level of knowledge about HIV. The results are very significant and allowed the students to analyze and learn from the people who participated in the education program. The nursing students learned from this activity that the young people have a lack of understanding about HIV. The nursing students learned that the 
ongoing education of students in the community is a process and more and different ideas will need to be presented so that students can gain a clear understanding of the problem of HIV/AIDS.

Developing strategies that are effective in educating youth on HIV can affect their understanding of the disease. Understanding the disease of HIV and what actions prevent the spread of the disease can have significant long range impact on the productivity of the country and wellbeing of the citizens of the country. Included in these consequences would be less utilization of health care resources in caring for those afflicted with the illness and more compassion toward those that have contracted the illness. The long range goal of this work is to provide information, create a better understanding, raise awareness, and encourage the development of safe behaviors to minimize the risk of infection. A change in perception among youth about HIV/AIDS, and development of better prevention strategies for youth can be achieved if there will be better strategies to address the current problems associated with HIV/AIDS in Indonesia.

In this concept, the strategy used to assess any change in the behavior of young people about HIV / AIDS prevention. Effective strategies are used for preventing all routes of HIV/AIDS transmission. The most effective prevention programs are those that use a combination of strategies to achieve maximum impact. One of the strategies that found in the literature review is to create a group of young people who are trained periodically related to HIV prevention, so that effective strategies can be seen and behavioral changes can be assessed easily. Before implementing a strategy that has been made, then that person should give approach to the relevant organizations or to the community. Also in the literature review, those strategies are also applied and implemented in the areas of business and management to find ways and different activities with others so that organizational goals can be achieved. In management, the strategy reflects the insight and intuition of the strategies or business owner, and it becomes clear over time as a pattern in a stream of decisions.

The strategies that must reflect people made the thoughts, feelings, ideas, and wants youth and mold them along with the purpose. Strategies are effective ways to achieve goals made in a different way. To make the strategy will require a good planning is to look at the needs and goals of the interests of society and especially young people in HIV prevention. In addition, with the analysis and evaluation of the activity or activities that have been done then this strategy is practiced in different ways and methods than usual. So that young people can change their behavior and can help prevent HIV among young people.

\section{CONCLUSION}

HIV knowledge is an important factor influencing HIV risk perceptions and risk behaviors especially among youth. Understanding the unique dynamics of the HIV epidemic among youth is critical to developing and implementing effective prevention and treatment programs. This program can be done by a nurse educator, where the rising HIV caseload increases the demand for care and support in health facilities and 
communities. The HIV prevention for youth should include education for behavior change, information about risk and side effect, condom promotion and provision, STI treatment, and harm reduction. To conduct prevention and promotion programs, nurses must perform the assessment, data collection and see the program was run in youth has not been successful, and then the nurse should plan an effective and better strategy to address the identified needs. This is a process where the community health nurse is always evaluating the plan so that the best ideas are identified for working with this population.

Concept analysis is the basis for theory development. Although the identified attributes may enhance understanding of strategy, further work is needed to operationalize the concept. If nurse educators are to view "strategies" as more than resource provision and negotiation, they must develop a process which addresses the development, implementation, and evaluation of their work in the community.. With use of the best strategies, nurse educator can teach nursing students how best to reach youth and other people in the community to prevent HIV.

\section{REFERENCES}

Amfar AIDS Research. (2010). Youth and HIV/AIDS in the United States: Challenges and Opportunities for Prevention. Washington, DC: Amfar, The Foundation for AIDS Research.

Asian Development Bank. (2008). Education and Skills: Strategies for Accelerated Development in Asia and the Pacific. Asian Development Bank, 1-123.

CDC HIV/AIDS. (2008). HIV/AIDS among Youth. CDC HIV/AIDS Resources, 1-5.

Cherie, A., Mitkie, G., Ismail, S., \& Berhane, Y. (2005, April). Perceived Suddiciency and Usefulness of IEC Materials and Methods Related to HIV/AIDS among High School Youth in Addis Ababa, Ethiopia. African Journal of Reproductive Health, 9, 66-77.

Children \& Youth Unit. (2006). HIV/AIDS Prevention among Youth: What Works? Washington DC: World Bank.

Dimbuene, Z. T., \& Defo, B. K. (2011). Fostering Accurate HIV/AIDS Knowledge among Unmarried Youths in Cameroon: Do Family Environment and Peers Matter? BMC Public Health, 1-12.

Foster, C. B., McLaughlin, N., Gray, A., Ogedegbe, A., Hageman, I., Knowlton, C., . . . Beeder, A. (2010). Reducing HIV and AIDS through Prevention (RHAP): A Theoretically Based Approach for Teaching HIV Prevention to Adolescents through an Exploration of PopularMusic. Journal of Urban Health, 87, 440-451.

Hamza, K. M., \& Wickman, P.-o. (2008). Describing and Analyzing Learning in Action: An Empirical Study of the Importance of Misconceptions in Learning Science. Wiley Periodicals, Inc, 141-164.

Hunger, D., \& Wheelen, T. L. (2011). Essentials of Strategic Management. US: HR Folka International.

Mccoy, H., Malow, R., Edwards, R. W., Thurland, A., \& Rosenberg, R. (2007). A Strategy for Improving Community Effectiveness of HIV/AIDS Intervention 
Design: The Community Readiness Modelin the Caribbean. Informa Healthcare USA, Inc, 1579-1592. doi:10.1080/1086080701212535

Miller, K. S., Forehand, R., Wiegand, R., Fasula, A. M., Armistead, L., Long, N., \& Wyckoff, S. C. (2011). Making HIV Prevention Programming Count: Identifying Predictors of Success in a Parent-Based HIV Prevention Program for Youth. AIDS Education and Prevention, 38-53.

Ministry of Health Republic of Indonesia. (2014). Laporan terakhir kemenkes. Retrieved from http://spiritia.or.id/Stats/StatCurr.php?lang=id\&gg=1

National HIV/AIDS Strategy. (2011). Implementing the National HIV/AIDS Strategy. US: US Department of Housing and Urban Development.

Oblinger, D. (2006). Simulations, Games, and Learning. Educause, 1-6.

Oladepo, O., \& Fayemi, M. M. (2011). Perceptions about Sexual Abstinence and Knowledge of HIV/AIDS Prevention among In-School Adolescents in a Western Nigerian City. BMC Public Health, 1-10.

Palekar, R., Pettifor, A., Behets, F., \& MacPhail, C. (2008). Association Between Knowing Someone Who Died of AIDS and Behavior Change Among South African Youth. Springer Science+Business Media, 903-912.

Romero, L. M., Galbraith, J. S., Williams, L. W., \& Gloppen, K. M. (2011). HIV Prevention Among African American Youth: How Well Have Evidence-Based Interventions Addressed Key Theoretical. AIDS Behavior, 976-991.

Rose, C., Wang, Y.-C., Cui, Y., Arguello, J., Stegmann, K., Weinberger, A., \& Fischer, F. (2008). Analyzing Collaborative Learning Processes Automatically: Exploiting the Advances of Computational Linguistics in Computer-Supported Collaborative Learning. International Society of the Learning Sciences, 237-271.

Wang, S., \& Keats, D. (2005). Developing an Innovative Cross-Cultural Strategy to Promote HIV/AIDS Prevention in Different Ethnic Cultural Groups of China. AIDS Care, 874-891.

Wyatt, T. J., \& Oswalt, S. B. (2011). Letting Students Be Innovative! Using MiniGrants to Fund Student-Designed HIV/AIDS Education. Health Promotion Practice, 413-424. 